\title{
AULAS PRÁTICAS COMO ESTRATÉGIA PARA O CONHECIMENTO EM BOTÂNICA NO ENSINO FUNDAMENTAL
}

\author{
A. P. M. SILVA ${ }^{1}$, M. F. S. SILVA ${ }^{1 *}$, F. M. R. ROCHA ${ }^{2}$ e I. M. ANDRADE ${ }^{1}$ \\ ${ }^{1}$ Herbário Delta do Parnaíba- HDELTA, Universidade Federal do Piauí - Campus Ministro Reis Velloso \\ ${ }^{2}$ Comissão Ilha Ativa-CIA \\ lenolysilva@hotmail.com
}

Artigo submetido em agosto/2014 e aceito em dezembro/2015

DOI: 10.15628/holos.2015.2347

\section{RESUMO}

$\mathrm{Na}$ aplicação dos conteúdos da disciplina Ciências Naturais à teoria não deveria ser desvinculada da prática, pois esta metodologia é imprescindível para construção do conhecimento científico dos alunos. Assim, objetivouse investigar a viabilidade de aulas práticas para alunos do 7으 ano do Ensino Fundamental, em duas escolas estaduais no município de Parnaíba, Piauí, como estratégias para facilitar o ensino-aprendizagem em conteúdo de Botânica. Foram aplicados questionários antes e após cada aula prática para verificar a construção de conhecimento. Os resultados demonstraram aumento no número de respostas corretas após as aulas práticas nas duas escolas alvo da pesquisa. Concluiu-se que o ensino de ciências, pode ser melhorado a partir de iniciativas simples, como realização de aula prática dentro da sala ou usando os espaços verdes da escola.

PALAVRAS-CHAVE: Construção do conhecimento científico, Ensino de botânica, Metodologia de ensino.

\section{PRACTICAL AS A STRATEGY FOR KNOWLEDGE IN BOTANY IN ELEMENTARY EDUCATION}

\begin{abstract}
When teaching the subject area of Natural Science, theoretical and practical aspects should not be separated, since both viewpoints are essential for ensuring that the students acquire a well-formed foundation of scientific knowledge. The objective of this study was therefore to investigate the viability of practical classes for students in the seventh year of Basic Education, in two state schools of the municipality of Parnaíba, Piauí, as a strategy for facilitating teaching and
\end{abstract}

learning in the subject area of Botany. Questionnaires were used before and after each practical class to study the acquisition of the students' knowledge. The results demonstrated an increase in the number of correct answers after the practical classes, in the two schools studied. Our conclusion is that scientific teaching can be improved by simple initiatives such as carrying out practical sessions within the classroom or by using the green spaces within the school..

KEYWORDS: Construction of scientific knowledge, Teaching botany, teaching methodology. 


\section{INTRODUÇÃO}

O modelo tradicional de ensino baseado na exposição oral do conteúdo disciplinar com ênfase em exercícios e memorização ainda é largamente utilizado por grande parte dos educadores, tanto no Ensino Fundamental quanto no Ensino Médio. Nessa direção, o conhecimento é tratado como um conjunto de informações que são transmitidas dos professores para os alunos. Na maioria das vezes, essas informações não são assimiladas de maneira reflexiva, mas memorizadas momentaneamente, resultando em falta de interesse e não aprendizado dos alunos (CARRAHER, 1986).

Ensinar consiste em um processo contínuo que objetiva garantir o aperfeiçoamento das relações humanas em sociedade. Neste processo é imprescindível realizar ações educativas direcionadas para uma interação harmônica do indivíduo com o ambiente em que estão inseridos. O Ensino de Ciências, portanto, é de fundamental importância para o desenvolvimento do espírito científico (ARAÚJO; MARQUES, 2010).

Conforme os Parâmetros Curriculares (BRASIL, 2001), o ensino de Ciências Naturais deve contribuir para aquisição de postura reflexiva, crítica, questionadora e investigativa, onde o discente seja formado para criticidade e ação. Neste sentido, dentre os objetivos propostos nos PCN para o Ensino de Ciências no Ensino Fundamental vale destacar a ação de:

Desenvolver no estudante competências que lhe permitam compreender o mundo e atuar sobre este como cidadão: isso implica a capacidade de compreender a natureza como um todo dinâmico e o ser humano como agente de transformações do mundo em que vive em relação essencial com os demais seres vivos e outros componentes do ambiente (BRASIL, 1997, p.39).

Segundo Brasil $(1998,2002)$ e Paraná $(2005)$, é exigido da escola a formação de alunoscidadãos conscientes e críticos, interferindo de forma positiva na comunidade em que vivem. Ao professor cabe conhecer a cultura científica; a importância da Ciência para o desenvolvimento da sociedade; o contexto interdisciplinar; e os temas transversais que surgem a partir do desenvolvimento científico. E ainda, deve conhecer o aluno e sua comunidade, pois o processo de ensino-aprendizagem acontece a partir da partilha de conhecimentos trazidos pelo aluno e pelo professor.

Atualmente, o modelo de ensino de ciências utilizado tem merecido críticas que indicam a necessidade de reorientar as investigações para além das preconcepções dos alunos, por não considerar que o conhecimento científico tem exigências relativas a valores humanos, à construção de uma visão de Ciência e as suas relações com a Tecnologia e a Sociedade (BRASIL, 1998).

Para Silva e Andrade (2008), as metodologias de ensino devem fazer associação entre o que é aprendido na sala de aula e o que o aluno vivencia em seu cotidiano.

O ensino dos conteúdos, inclusive o de Botânica, tanto no Ensino Fundamental como no Médio, é considerado pelos discentes complexo devido à forma como é ministrado, totalmente descritivo, causando aversão e desinteresse (COUTINHO, 2004; GARCIA, 2000).

No Ensino Fundamental, o estudo sobre plantas é ministrado de forma elementar, onde são trabalhadas definições de termos e apresentados conteúdos, tais como, morfologia externa, 
reprodução, nutrição, fisiologia e distribuição. O estudo de plantas é realizado pela área denominada Botânica ou Fitologia. No Ensino Médio, por exemplo, sabe-se que muitos educadores "fogem" das aulas de botânica relegando-as ao final da programação do ano letivo por medo e insegurança em abordar o assunto. Reclamam que há grande dificuldade em desenvolver atividades práticas que despertem curiosidade do aluno e mostrem a utilidade daquele conhecimento no seu dia-a-dia (SANTOS; CECCANTINI, 2004).

O estudo das plantas ainda é realizado de maneira desestimuladora e de forma diferente da realidade da escola e da comunidade. Resumem-se em aulas teóricas, onde são utilizadas receitas prontas retiradas de livros didáticos, na maioria das vezes, apresentadas apenas em datas comemorativas, de forma pontual, como por exemplo, o dia da árvore, semana do meio ambiente ou em feira de ciências (DIAS et al., 2009).

As aulas práticas, como método didático, são decisivas para o aprendizado das Ciências, pois contribuem para a formação científica, tendo em vista que aguça a observação, manipulação e construção de modelo. As aulas práticas devem permitir ao estudante observar, vivenciar e discutir conjunto de experiências e fenômenos biológicos e físico-químicos relacionados com seu cotidiano (PIOCHON, 2002).

As dificuldades em ensinar e aprender botânica acontecem tanto entre os estudantes quanto entre os professores. A aquisição do conhecimento em botânica é prejudicada não somente pela falta de estímulo em observar e interagir com as plantas, como também pela precariedade de equipamentos, métodos e tecnologias que possam auxiliar no aprendizado (ARRUDA; LABURÚ, 1996; CECCANTINI, 2006).

De acordo com Sampaio (1996), a prática educativa com aula de campo, por exemplo, trabalhada com dedicação, é considerada uma ruptura das atividades realizadas em classe, contribuindo para o aprofundamento dos conteúdos abordados em sala de aula, e para a formação do aluno no campo social, intelectual e afetivo, tornando momentos de aprendizagem inesquecíveis.

Para Pereira e Putzke (1996):

\begin{abstract}
Uma aula de campo, não se refere apenas em visitas a matas ou florestas, mas a qualquer ambiente diferente de sala de aula, podendo inclusive ser o pátio da escola, ruas do bairro ou parques, lugares onde os estudantes podem ser motivados a participarem das ações.
\end{abstract}

Diante de tais constatações e na busca de alternativas para contribuir com a melhoria da qualidade do ensino de Botânica no Ensino Fundamental, objetivou-se investigar o nível de aprendizagem dos alunos das turmas do 70 ano em duas escolas estaduais, localizadas no município de Parnaíba, Piauí, antes e após a utilização de aulas práticas, como estratégia para facilitar o ensino-aprendizagem em Botânica. Além disto, verificar o impacto desta metodologia para processo de ensino-aprendizagem.

\title{
2 METODOLOGIA
}

A pesquisa foi realizada em duas escolas da rede estadual de ensino, Unidade Escolar Edison da Paz Cunha e Unidade Escolar Cândido Oliveira, no município de Parnaíba, situada no extremo 
norte do estado Piauí, distante $339 \mathrm{~km}$ da capital, Teresina. Parnaíba possui uma área de $453 \mathrm{Km}^{2}$ e uma população de 145.729 (IBGE, 2010). Segundo dados do Instituto de Desenvolvimento de Educação Básica (IDEB) e da Secretaria de Educação do Estado, o município de Parnaíba possui um total de 94 escolas públicas municipais, 27 escolas públicas estaduais e 14 escolas particulares.

Para o desenvolvimento da pesquisa, um questionário de seis questões foi aplicado antes da aula prática, e outro questionário de oito questões aplicado após cada aula prática, aos 60 alunos (30 em cada escola) de duas turmas do sétimo ano do Ensino Fundamental durante o período de maio a novembro de 2011. As questões foram fechadas e de múltipla escolha sobre o conteúdo das angiospermas: raiz, caule, folha, flor e reprodução. Cada questionário foi respondido individualmente.

Para a seleção das aulas práticas foram consultados livros didáticos para a elaboração ou adaptação de roteiros de experimentos de acordo com a série, as condições da escola e o compromisso de estimular o raciocínio dos alunos e a participação nas atividades práticas. As experiências selecionadas foram testadas para que fosse possível detectar antecipadamente os problemas que pudessem vir a ocorrer em sala de aula e também para verificação do tempo, para não exceder o período concedido para a atividade.

As aulas práticas foram realizadas na sala de aula e quando possível no espaço de área verde da escola. Para todas as práticas procurou-se usar material de fácil acesso levando em consideração o cuidado com o meio ambiente e também o fato das escolas não possuírem laboratórios.

No início da realização de cada prática foi entregue o roteiro de aula e introduzido o assunto, objeto da atividade, aos alunos para o levantamento das possíveis concepções que possuíam a respeito do mesmo. Posteriormente, as turmas foram divididas em grupos de cinco alunos para que a prática pudesse ser realizada. Estruturas da planta (vegetativas e reprodutivas) foram utilizadas para reconhecimento de suas partes e funções, além disto, foi solicitado que os alunos ilustrassem as estruturas estudadas.

$\mathrm{Na}$ aula prática sobre raiz e caule foram utilizados tipos de raízes para que os alunos observassem e identificassem suas partes. Na prática sobre o conteúdo folhas foi possível observar o fenômeno da transpiração e da fotossíntese, além do reconhecimento das partes destas estruturas. E na prática sobre reprodução foram utilizadas flores de Hibiscus sp. (Malvaceae) para o reconhecimento de suas estruturas, maquetes mostrando o processo de polinização e reprodução, além de observação do processo de germinação de sementes.

Após cada prática foi realizada a análise de cada atividade com discussões sobre os temas apresentados, e assim então, aplicado o segundo questionário para avaliar o nível de aprendizagem sobre os conteúdos ministrados.

As escolas foram nomeadas como E1 e E2, Unidade Escolar Edison da Paz Cunha e Unidade Escolar Cândido Oliveira, respectivamente.

\section{RESULTADOS E DISCUSSÕES}

O número de respostas corretas dos questionários aplicados, nas duas escolas onde foi realizada a pesquisa, foi maior após as realizações das aulas práticas, quando comparado ao 
resultado obtido com os questionários antes das aulas práticas. Assim, este resultado indica que houve construção de conhecimento por parte dos alunos em relação aos conteúdos propostos durante a realização das aulas teórico/práticas (Tab. 1).

Tabela 1- Porcentagem de respostas corretas obtidas nas questões aplicadas antes das práticas (Ap) e depois das aulas práticas (Dp) na Unidade Escolar Edison da Paz Cunha (E1) e na Unidade Escolar Cândido Oliveira (E2).

\begin{tabular}{|c|c|c|c|c|}
\hline Questões & $\begin{array}{l}\text { Ap } \\
\text { E1 }\end{array}$ & $\begin{array}{l}\text { Dp } \\
\text { E1 }\end{array}$ & $\begin{array}{l}\text { Ap } \\
\text { E2 }\end{array}$ & $\begin{array}{l}\text { Dp } \\
\text { E2 }\end{array}$ \\
\hline \multicolumn{5}{|l|}{ RAIZ } \\
\hline 1. Quais as principais funções das raízes? & $43 \%$ & $90 \%$ & $47 \%$ & $70 \%$ \\
\hline 2. Qual a função das raízes tuberosas? & $37 \%$ & $77 \%$ & $50 \%$ & $67 \%$ \\
\hline $\begin{array}{l}\text { 3. Quais os tipos especiais de raízes que são utilizadas em nossa } \\
\text { alimentação? }\end{array}$ & $43 \%$ & $73 \%$ & $73 \%$ & $90 \%$ \\
\hline $\begin{array}{l}\text { 4. Quais plantas possuem raízes sugadoras e sugam a seiva da planta } \\
\text { hospedeira? }\end{array}$ & $43 \%$ & $73 \%$ & $87 \%$ & $90 \%$ \\
\hline 5. Quais os tipos de raízes que ocorrem em plantas de mangue? & $64 \%$ & $80 \%$ & $87 \%$ & $93 \%$ \\
\hline 6. Desenhe uma raiz e escreva o nome de suas regiões. & $87 \%$ & $93 \%$ & $87 \%$ & $90 \%$ \\
\hline \multicolumn{5}{|l|}{ CAULE } \\
\hline 1. Quais as principais funções do caule? & $60 \%$ & $83 \%$ & $83 \%$ & $87 \%$ \\
\hline 2. Qual a importância das gemas ou "brotos" apicais e laterais do caule? & $73 \%$ & $90 \%$ & $47 \%$ & $63 \%$ \\
\hline 3. Qual a diferença entre o caule de bambu e cana-de-açúcar? & $90 \%$ & $100 \%$ & $80 \%$ & $97 \%$ \\
\hline 4. O caule do tipo estipe é típico de uma palmeira? & $67 \%$ & $70 \%$ & $53 \%$ & $57 \%$ \\
\hline $\begin{array}{l}\text { 5. A batata inglesa (tubérculo) e a cebola (bulbo) são tipos de caules } \\
\text { subterrâneos. O que há em comum entre estes caules? }\end{array}$ & $83 \%$ & $97 \%$ & $77 \%$ & $80 \%$ \\
\hline $\begin{array}{l}\text { 6. Às vezes o caule ou ramos sofrem modificações formando estruturas } \\
\text { especiais. Como são chamadas estas estruturas? }\end{array}$ & $40 \%$ & $57 \%$ & $53 \%$ & $60 \%$ \\
\hline
\end{tabular}

\section{FOLHA}

1. Quais as principais funções das folhas?

2. Quais as principais partes de uma folha "completa"?

3. Do que a planta precisa para realizar a fotossíntese?

4. O que a planta produz através da fotossíntese?

5. Qual a importância da transpiração em dias quentes para a planta?

6. Quais os tipos especiais de modificações foliares? FLOR

1. Qual a função das flores nas plantas angiospermas?

2. De quais partes a flor é constituída?

3. As sépalas são formadas por quais estruturas?

4. As pétalas são formadas por quais estruturas?

5. Os estames são formados por:

6. O conjunto de carpelos forma a parte feminina da flor o gineceu. Os carpelos são formados por quais estruturas?

\section{REPRODUÇÃO}

\begin{tabular}{l|l|l|l|l}
\hline 1. Quais os tipos de reprodução ocorrem nas angiospermas? & $67 \%$ & $90 \%$ & $53 \%$ & $93 \%$ \\
\hline 2. A planta pode reproduzir-se através de uma folha? & $33 \%$ & $57 \%$ & $33 \%$ & $73 \%$ \\
\hline 3. Você acredita que o tubérculo pode dar origem a uma planta? & $67 \%$ & $80 \%$ & $63 \%$ & $87 \%$ \\
\hline 4. Há formação de uma nova planta através da semente? & $93 \%$ & $97 \%$ & $90 \%$ & $93 \%$ \\
\hline $\begin{array}{l}\text { 5. Quais estruturas existem nos caules que facilitam a reprodução } \\
\text { assexuada? }\end{array}$ & $67 \%$ & $97 \%$ & $57 \%$ & $67 \%$ \\
\hline 6. Onde são produzidos os grãos de pólen nas angiospermas? . & $70 \%$ & $73 \%$ & $50 \%$ & $80 \%$ \\
\hline
\end{tabular}




\subsection{Prática sobre raiz}

O resultado do questionário aplicado após a prática sobre raiz evidenciou que os alunos da E2 apresentavam mais conhecimento prévio sobre o tema quando comparados aos alunos da E1 para todas as questões.

Na E1 o número de alunos que conhecem as principais funções das raízes aumentou em $46 \%$ enquanto na E2 o aumento foi de $23 \%$. Para as questões dois, três, quatro e cinco a porcentagem foi maior em $40 \%, 30 \%, 30 \%$ e 16\%, respectivamente, na E1, enquanto na E2 foi de $17 \%, 17 \%, 3 \%, 6 \%$ e $3 \%$, respectivamente, para as mesmas questões.

Os resultados obtidos mostram o contraste entre uma condição prévia frente a um determinado conteúdo e a condição após aplicação de novas concepções sobre o mesmo assunto, ou seja, a prática utilizada gera mais conhecimento.

É indispensável para a realização de aprendizagens significativas que o aluno manifeste disposição para a mesma, estabelecendo relações entre o novo e o que já é conhecido, possibilitando esclarecer e detalhar conceitos. Esta condição é denominada de enfoque profundo, no sentido de Entwistle (1988). Ao mesmo tempo em que são construídos significados sobre os conteúdos de ensino, os alunos constroem representações sobre a própria situação didática, que pode ser percebida como estimulante e desafiadora ou, pelo contrário, como intratável e tediosa, desprovida de interesse ou inatingível para suas possibilidades.

De acordo com o trabalho de Santos (2007), o sentido da aplicação das aulas práticas é que a ciência encaminha o pesquisador para rupturas de fronteiras, métodos, experimentos e experiências de verdades transitórias.

\subsection{Prática sobre caule}

Embora os alunos das duas Unidades de Ensino tenham obtido mais êxito nas respostas do questionário aplicado após a aula prática, observou-se que o número de alunos que conhecem as principais funções do caule aumentou em $4 \%$ na E2 enquanto na E1 foi de $23 \%$. Para as questões de dois a seis a porcentagem obtida foi de $16 \%, 10 \%, 3 \%, 13 \%$ e $17 \%$, respectivamente, na E1 enquanto na E2 foi de $16 \%, 17 \%, 4 \%$, $3 \%$ e $7 \%$.

Os dados obtidos estão de acordo com Prigol e Giannotti (2008), tendo em vista que, vivemos em um mundo em constante transformação. $O$ método que enfatiza a realização de atividades práticas é de fundamental importância neste processo de ensino, fazendo com que o aluno aprenda, compreenda e fortaleça o conhecimento adquirido.

\subsection{Prática sobre folha}

O número de acertos em relação ao conhecimento das principais funções das folhas foi de $13 \%$ após a aplicação da prática. Na E1 houve aumento nos acertos das questões: dois (3\%), três e quatro $(10 \%)$, cinco $(7 \%)$ e seis $(20 \%)$. Na E2, por sua vez, os resultados foram os mesmos para as questões dois (26\%), três (20\%), quatro (10\%), cinco (40\%) e seis (33\%), ou seja, apresentou média maior de acertos.

A realização de aula prática utiliza-se de meios multidimensionais que podem facilitar a aprendizagem. Segundo Bordenave e Pereira (1995), os meios sensoriais podem ter as seguintes 
funções: facilitar o reconhecimento e descrição dos objetos; facilitar a comparação entre dois ou mais objetos, e consequentemente, a identificação de semelhanças e diferenças; mostrar a relação entre partes de um todo; descrever o funcionamento de processos, inclusive as etapas ou passos sucessivos; apresentar situações complexas para a uma análise. Além disto, os meios multissensoriais não tem somente funções cognitivas, mas também podem aplicar-se ao domínio afetivo, como por exemplo, sensibilizar mais os alunos com as questões ambientais.

\subsection{Prática sobre flor}

Assim como na aplicação de práticas para o estudo da morfologia dos órgãos vegetativos, a prática sobre flor foi bastante estimulante, sendo constatado pelo número significativo de acertos em todas as questões em ambas as escolas. O número de acertos sobre a questão que tratava das principais funções das flores nas angiospermas foi maior em $37 \%$ quando comparado com os acertos antes da realização das práticas na E1, enquanto na E2 foi somente de $4 \%$. Para as questões dois a seis as porcentagens na E1 foram de $16 \%, 10 \%, 13 \%, 36 \%$ e $37 \%$, respectivamente, enquanto, na E2 foram de $23 \%, 10 \%, 6 \%, 16 \%$ e $7 \%$, respectivamente.

Prigol e Giannotti (2008) e Menezes et al. (2015) encontraram resultados semelhantes sobre o conteúdo "Flor", ou seja, o maior número de acertos foi após a realização das aulas práticas.

\subsection{Prática sobre reprodução}

Pode ser constatado que nas duas escolas houve um número significativo de respostas corretas após a prática sobre reprodução nas angiospermas, corroborando com o trabalho de Pinto, Martins e Joaquim (2009) que encontraram aumento significativo nas respostas em todas as questões propostas após a realização dos experimentos a alunos de ensino Fundamental da 6ạ série em São José dos Campos/SP, em comparação com as respostas do questionário prévio realizado.

Diferentemente, Soares (2005) ao aplicar questionário sobre o tópico flor e reprodução das plantas evidenciou que as concepções prévias dos alunos não foram totalmente substituídas pelos novos conceitos científicos apresentados pela professora regente.

\subsection{Ilustrações produzidas pelos alunos das Escolas E1 e E2}

A construção do conhecimento pode ser evidenciada nos desenhos produzidos pelos alunos antes, durante e depois das práticas. Os desenhos produzidos após as práticas mostram um conhecimento mais elaborado, pois os alunos conseguem identificar e nomear as estruturas constituintes de cada órgão (Fig. 1 e 2).

A substituição de aula teórica por práticas pedagógicas possibilitam formar um sujeito apto a construir e reconstruir conhecimentos (BORGES; LIMA, 2007; PINTO; MARTINS; JOAQUIM, 2009). 
A
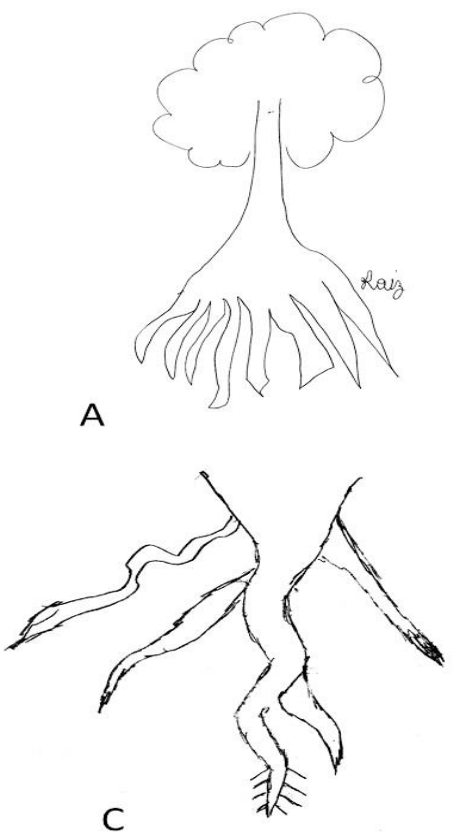
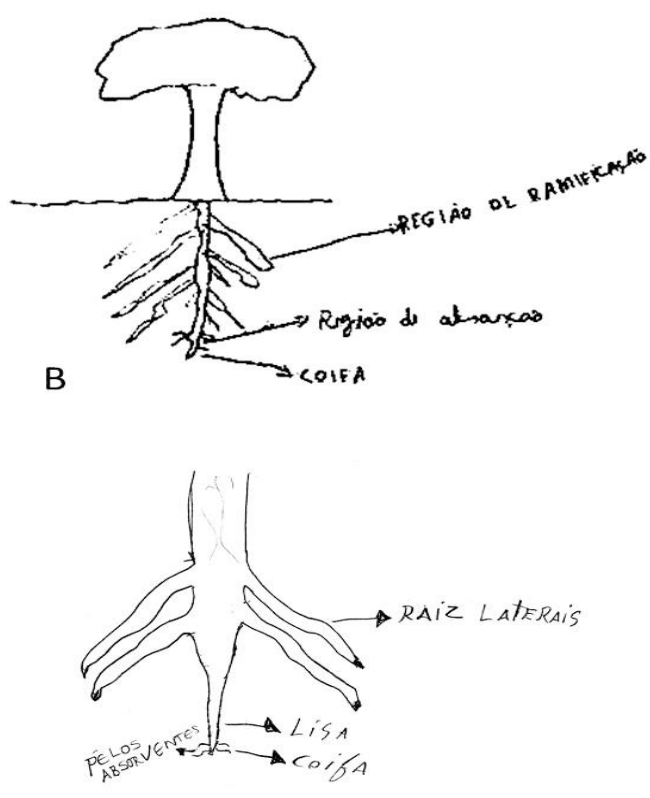

$\mathrm{D}$

Figura 1- Representações da estrutura raiz feitas por alunos antes e após as práticas, respectivamente: A-B. Unidade Escolar Edson da Paz Cunha; C-D. Unidade Escolar Cândido Oliveira.

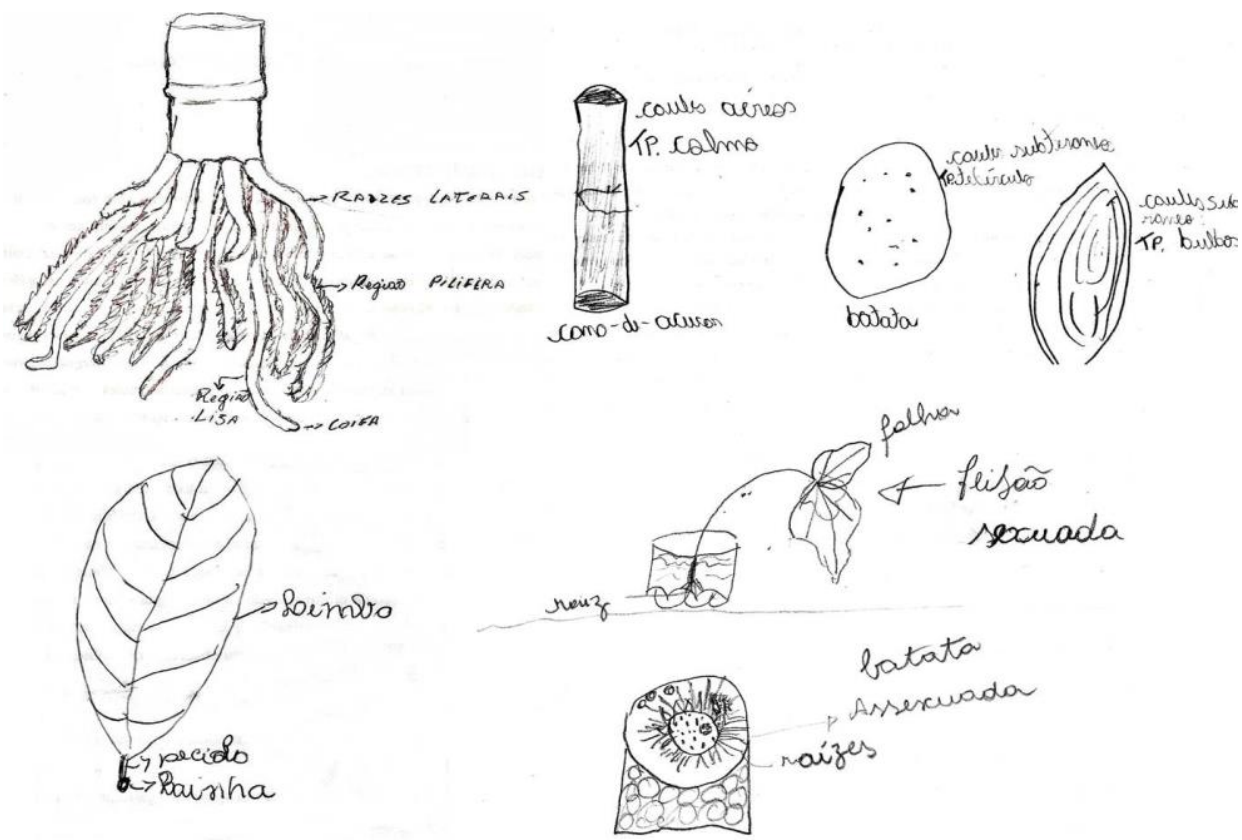

Figura 2. Desenhos realizados pelos alunos durante as aulas práticas de Botânica.

Semelhante ao estudo de Silva e Cavassan (2006), foi verificado que os alunos reconheceram as estruturas e os organismos estudados após a realização da aula prática no campo.

A utilização de exemplares naturais possibilitam a análise de estruturas com riqueza de detalhe diferentemente do que ocorre ao observar os desenhos do livro, por exemplo. Como afirma Araújo (2011, p.18): 
O uso de material vegetal em sala de aula promove uma grande interação entre os alunos e entre os mesmos e o professor favorecendo a aprendizagem, pois o aluno tem em suas mãos a "teoria palpável", aquelas definições dos livros se tornam reais.

As principais funções das aulas práticas reconhecidas na literatura em relação ao ensino de Ciências, são: despertar e manter o interesse dos alunos; envolver os estudantes em investigações científicas; desenvolver capacidade de resolver problemas; compreender conceitos básicos e desenvolver habilidades (KRASILCHIK, 1996).

Embora a contribuição intrínseca dos métodos e das técnicas de ensino sejam importantes para o processo ensino-aprendizagem, devemos lembrar do grande significado que os valores, a atitude e o comportamento pessoal que o professor deve ter frente a este processo. "Ele é o grande contagiante para a procura e a descoberta de novos horizontes" (BORDENAVE; PEREIRA, 1995).

Silva e Andrade (2008) investigaram os fatores que levavam os alunos a terem dificuldades no aprendizado dos conteúdos de Botânica. A pesquisa identificou diferenças quanto aos métodos de ensino utilizados pelos professores, embora os conteúdos trabalhados fossem os mesmos. Foi detectado deficiência no ensino de Botânica, considerado de pouca importância, e que a falta de interesse dos alunos pelo conteúdo de Botânica provavelmente estava relacionada a didática aplicada pelo professor, muitas vezes limitada apenas à explicação do conteúdo do livro texto, a não produção de materiais didáticos e ao não desenvolvimento de métodos alternativos. Outros fatores limitantes, como a carga horária insuficiente e a falta de recursos didáticos nas escolas também contribuíam para esse quadro.

Nas escolas públicas, principalmente, são notórias as dificuldades na realização de atividades práticas de qualidade. Apesar das condições precárias apresentadas pela maioria das escolas com relação a falta de materiais didáticos e espaço para atividades de laboratório, é possível contornar esses problemas ou parte desses, fazendo adaptação de ambientes para aula prática e utilizando materiais de baixo custo. Essas ações proporcionam aprendizado mais eficiente e motivador do que as tradicionais aulas meramente expositivas.

É importante considerar, também, que as condições de sobrecarga de trabalho no magistério dificulta a realização do trabalho docente eficaz por falta de tempo e que a maioria dos livros didáticos, no aspecto da área de botânica, não são elaborados de forma a atender às necessidades prática dos professores (KRASILCHIK, 1996).

Durante as atividades práticas foi verificado que os alunos não tinham familiaridade com esse tipo de aula, pois se encontram habituados ao padrão de aula teórico-expositiva. Entretanto, o interesse e motivação dos alunos pelas atividades práticas realizadas foram demonstrados através de questionamentos, respostas e comentários acerca dos assuntos abordados. Para que as aulas sejam proveitosas, faz-se necessário que tanto aluno como professor se sintam motivados.

Além da escolha da melhor metodologia para a apresentação da prática, o professor deve levar em conta outros fatores, tais como, motivação no aprendiz, ferramentas e materiais necessários para a prática, auxílios visuais para compreender a explanação verbal, exercício pelo aprendiz e aplicação real no campo para facilitar a fixação e generalização (BORDENAVE; PEREIRA, 1995). 
Considera-se que o instrumento utilizado para avaliar os conhecimentos prévios e posteriores a aplicação das práticas foi eficaz, pois tornou possível, além de verificar o nível de conhecimento, realizar uma reflexão conjunta sobre o processo de aprendizagem desenvolvido. Segundo Miras (2006), da perspectiva dos alunos, este instrumento possibilita voltar a considerar em determinados momentos que suas respostas iniciais podem ser uma ajuda para tomada de consciência das mudanças ocorridas a respeito. De maneira similar, da perspectiva do professor, esta retrospectiva pode ser útil para avaliar o caminho percorrido pelos alunos e, por que não, para dar-lhes ânimo no caminho que ainda deve ser percorrido.

\section{CONSIDERAÇÕES FINAIS}

Diante do estudo realizado em duas escolas públicas da rede estadual de ensino no município de Parnaíba, Piauí, pode-se constatar que após as aulas teórico/práticas tanto os alunos da Unidade Escolar Edison da Paz Cunha quanto da Unidade Escolar Cândido Oliveira obtiveram aumento no número significativo de acertos em todos os conteúdos abordados, evidenciando a importância das aulas práticas para a aprendizagem, além do interesse em participar das atividades propostas e melhoria na relação aluno-aluno e professor-aluno.

Através de iniciativas simples, como realização de prática dentro da sala de aula, utilização do jardim ou áreas verdes da escola, algumas ruas arborizadas e praças próximas da escola, e utilização de material de fácil acesso e de baixo custo aulas práticas podem ser viabilizadas, podendo o conteúdo ser abordado de forma contextualizada com o vivenciado pelo o aluno no seu dia-a-dia. Estas ações estimulam os alunos a questionar e participar ativamente das atividades práticas, tornando-os produtores do conhecimento, e sujeitos ativos do processo de ensinoaprendizagem.

Alguns pontos devem ser considerados importantes para a realização de uma atividade prática, tais como: seleção da prática mais adequada ao conteúdo ministrado e a seriação do aluno, segurança do professor na aplicação da prática, preparação da atividade antes do início da aula, entrega de roteiro de aula prática, duração da atividade e fechamento da atividade.

\section{REFERÊNCIAS}

1. ARAÚJO, G.C. Botânica no ensino médio. 2011. 24 f. Monografia de (Graduação)- Cursos Consórcio Setentrional de Educação a Distância Universidade de Brasília e Universidade Estadual de Goiás Curso de Licenciatura em Biologia a Distância. Brasília, 2011.

2. ARAÚJO, J.N., MARQUES, A.S. Ensino de Botânica e a Educação básica na Amazônia. In: Diversidade Vegetal Brasileira; conhecimento, conservação e uso, In: $61^{\circ}$ Congresso Nacional de Botânica, Manaus, 5 a 10 set. 2010.

3. ARRUDA, S.M., LABURÚ, C.E. Considerações sobre a função do experimento no ensino de Ciências. Pesquisa em Ensino de Ciências e Matemáticas, Ciências \& Educação, Bauru, São Paulo, n.3, p.14-24. 1996.

4. BORDENAVE, J.D., PEREIRA, A.M. Estratégias de Ensino-aprendizagem. 16ạ. Ed. Petrópolis. Editora Vozes. 1995.318p.

5. BRASIL, Secretaria de Educação. Parâmetros Curriculares Nacionais: Ciências Naturais. 
Brasília: MEC, 1997. 136 p.

6. BRASIL. Ministério da Educação e do Desporto. Secretaria de Educação Fundamental Parâmetros Curriculares Nacionais: Terceiro e Quarto Ciclos do Ensino Fundamental-Ciências Naturais. Brasília: MEC/SEF, 1998.

7. BRASIL. Parâmetros Curriculares Nacionais: Ciências Naturais/ Ministério da Educação. Secretaria da Educação Fundamental. - 3a ed - Brasília: A Secretaria, 2001.

8. BRASIL. Ministério da Educação e do Desporto. Secretaria de Educação Média e Tecnológica PCN+ Ensino Médio: Orientações Educacionais complementares aos Parâmetros Curriculares Nacionais - Ciências da Natureza, Matemática e suas Tecnologias. Brasília: MEC/SEMTEC, 2002.

9. CARRAHER, T.N. Ensino de ciências e desenvolvimento cognitivo. Coletânea do II Encontro "Perspectivas do Ensino de Biologia". São Paulo, FEUSP, 1986.

10. CECCANTINI, G. Os tecidos vegetais têm três dimensões. Revista Brasileira de Botânica, v.29, n.2, p. 335-337. 2006.

11. COUTINHO, K. da S., DETMANN, E., GOMES, V.M., Da CUNHA, M. A compreensão dos alunos do segundo ciclo fundamental a respeito do conteúdo básico da biologia vegetal. 2004. In: 54 Congresso Nacional de Botânica. Belém, Pará, Brasil.2004

12. DIAS, C. M. J., SCHWARZ, A. E., VIEIRA, R. E. A Botânica além da sala de aula, 2009. Disponível em: www.diadiaeducação.pr.gov.br/portals/pde/arquivos/893-4.pdf. Acesso em 22 set 2010.

13. ENTWISTLE, N. Styles of learning and teaching. London: David Fulton. 1988.

14. GARCIA, M.F.F. Repensando a Botânica. In: Coletânea do 70 Encontro Perspectivas do Ensino de Biologia, São Paulo 2 a 4 fev 2000.

15. IBGE- Instituto Brasileiro de Geografia e Estatística, 2010. Disponível em: http://www.ibge. gov.br/cidadesat/topwindow.htm?1>. Acesso em: set. 2011.

16. IDEB - Índice de Desenvolvimento da Educação Básica. Disponível em: <http://ideb.meritt. com.br/\#\{"municipio_id":"2207603"\}>. Acesso em 2010.

17. KRASILCHIK, M. Prática de Ensino de Biologia. 3.Ed. São Paulo. Harbra, 1996.

18. MENEZES, L.C., SOUZA, V.C., NICOMEDES, M.P., SILVA, N.A., QUIRINO, M.R., OLIVEIRA, A.G., ANDRADE, R.R. D., SANTOS, B.A. Iniciativa para o Aprendizado de Botânica, (2008). Iniciativa para o Aprendizado de Botânica no Ensino Médio no Ensino Médio. In: XI Encontro de Iniciação a Docência. XI Encontro de Iniciação a Docência. Disponível em : <http://www.prac.ufpb.br/anais/xenex_xienid/xi_enid/prolicen/ANAIS/Area4/4CFTDCBSPLIC 03.pdf > Acesso 02/10/2015.

19. MIRAS, M. Um ponto de partida para a aprendizagem de novos conteúdos: os conhecimentos prévios. In: COLL, C. et al. O construtivismo na sala de aula. São Paulo: Ática, 2006.

20. PARANÁ. Secretaria da Educação do Estado do Paraná. Superintendência de Ensino. Departamento de Ensino Médio. Orientações Curriculares de Física. Paraná: SEED, 2005.

21. PEREIRA, A.B., PUTZKE, J. Ensino de Botânica e Ecologia: proposta metodológica. Porto Alegre: Sagra-Luzzatto, 1996. 184p. 
22. PINTO, T.V., MARTINS, I.M., JOAQUIM, W.M. A construção do conhecimento em Botânica através do Ensino Experimental. In: XIII Encontro Latino Americano de Iniciação Científica e IX Encontro Latino Americano de Pós-Graduação - Universidade do Vale do Paraíba, 2009.

23. PRIGOL, S., GIANNOTTI, S.M. A importância da utilização de práticas no processo de ensinoaprendizagem de ciências naturais enfocando a morfologia da flor. In: 10 Simpósio Nacional de Educação- XX Semana da Pedagogia. Unioeste-Cacavel/PR, 2008.

24. SANTOS, E.T.A. Educação ambiental na escola: conscientização da necessidade de proteção da camada de ozônio. Monografia (Pós-Graduação em Educação Ambiental). Rio grande do sul: (UFSM), 2007.

25. SANTOS, D. Y. A. C., CECCANTINI, G. Propostas para o ensino de botânica manual do curso para atualização de professores dos ensinos fundamental e médio - São Paulo. Universidade de São Paulo, 2004.

26. SILVA, I.C.V., ANDRADE, I.M. Estratégias de ensino de Botânica no ensino médio em uma escola pública e uma escola privada de Sobral - CE. Essentia, Sobral, v.10, n.1, p. 21-135, jun./nov. 2008.

27. SILVA, P.G.M., CAVASSAN, O. Avaliação das aulas práticas de Botânica em ecossistemas naturais considerando-se os desenhos dos alunos e os aspectos morfológicos e cognitivos envolvidos. Mimesis, Bauru, v. 27, n. 2, p. 33-46, 2006. 